\title{
AUGE Y DECADENCIA EN ESPAÑA EN LOS SIGLOS XVI Y XVII: ECONOMIA Y SOCIEDAD EN CASTILLA *
}

ANGEL GARCIA SANZ

Universidad de Valladolid

La atención de los historiadores por la historia económica y social de Castilla en los siglos xvi y xvil es relativamente reciente. No ocurre lo mismo con los aspectos políticos y diplomáticos, que han tenido notables tratadistas desde antiguo.

Es en los años sesenta del presente siglo cuando se puede situar el momento en que el interés por la economía y la sociedad castellanas del 500 y del 600 cobra un fuerte y decidido aliento que hoy perdura. En esta perspectiva, las estimables obras de Viñas Mey y Larraz aparecen como beneméritos antecedentes. En los años sesenta publica Carande la segunda edición corregida y aumentada del primer tomo de Carlos $V$ y sus banqueros; Domínguez Ortiz, sus estudios sobre la Hacienda de Felipe IV y sobre la sociedad española del siglo XVIII (1963), y también publican obras importantes de temática económico-social, relativas al período, Benassar, Salomon, Ulloa, Ruiz Martín, Guilarte, Basas, Chaunu, Vázquez de Prada. En 1955, Lapeyre había publicado su obra sobre los Ruiz de Medina, en la que reconstruía los complejos mecanismos del comercio internacional en la segunda mitad del xvi.

En los años setenta, y en lo que va de los ochenta, la atención de los investigadores por la historia económica y social castellana de los siglos XVI y xviI no ha dejado de aumentar, siendo ya numerosos los estudios que plantean el tema a nivel regional y local. Los historiadores españoles hemos de reconocer y agradecer a nuestros colegas de otros países — de Francia e Inglaterra, sobre. todo- la gran aportación que han hecho en los últimos treinta años al conocimiento de la historia económica y social de Castilla durante los siglos modernos.

Se intenta en estas breves páginas proponer un estado de la cuestión, a la

* Este escrito fue presentado como Comunicación al Coloquio Hispano-Holandés de Historia, celebrado en la Rijksuniversiteit de Leiden entre los días 1 al 4 de mayo de 1984. El autor desea expresar su agradecimiento a los colegas holandeses por la extraordinaria hospitalidad de que hicieron gala, y en especial a los profesores Lechner y Winius; también dedica un sentido recuerdo al profesor Van Oss, fallecido durante las jornadas. El autor agradece a la Secretaría de Redacción de la Revista el trabajo que ha realizado en la preparación de este escrito para su publicación. 
vista de las investigaciones recientes, sobre la evolución económica y social de los territorios de la Corona de Castilla a lo largo de las dos centurias que corren entre 1500 y 1700 . Dentro de los territorios castellanos prestaré especial atención a los más centrales —esto es, a las circunscripciones de León, Castilla la Vieja y Castilla la Nueva-, por considerar que la trayectoria económica y social de estos territorios durante el período contemplado es altamente representativa del sentido de la evolución histórica del conjunto de los territorios castellanos, de forma que los particulares comportamientos de algunas regiones castellanas periféricas —caso, por ejemplo, de la evolución demográfica de Galicia y Asturias en el siglo XVII - han de ser contemplados desde la perspectiva aportada por las regiones castellanas centrales a fin de valorar adecuadamente su significado.

La evolución económica y social de los territorios de la Corona de Aragón no es considerada en estas páginas, por estimar que no aporta nada decisivo al estado de la cuestión que interesa proponer en el marco de este Coloquio Hispano-Holandés de Historia. Por otra parte, conviene tener presente que los territorios aragoneses apenas concentraban un 20 por 100 de la población española en el siglo xvi, mientras que el 80 por 100 restante vivía en el espacio territorial castellano (Ruiz Martín, 1967).

El escrito consta de dos partes: la primera está dedicada a exponer los rasgos fundamentales de la evolución económica; la segunda aborda la cuestión del cambio social entre los siglos xvi y xviI. El autor es consciente de que ambos aspectos se hallan tan estrechamente interrelacionados que sólo el deseo de lograr una exposición lo más clara posible puede justificar un tratamiento por separado.

\section{LA ECONOMIA: DE LA EXPANSION DEL SIGLO XVI A LA «DECADENCIA» DEL SIGLO XVII}

Entre, aproximadamente, 1500 y 1700, la economía castellana conoció dos fases coyunturales de "larga duración» y opuestas por su signo: una expansiva, que arranca del siglo xv y culmina alrededor de los años ochenta del siglo xvi; otra depresiva, que toca fondo, según regiones, entre 1630 y 1680 , y que preside «la época de la decadencia».

El hecho de que la fase de expansión se inicie con anterioridad a la conversión de Castilla en el territorio nuclear del gran imperio de Carlos $\mathrm{V}$, e incluso con anterioridad al descubrimiento de América, descarta toda interpretación que pretenda atribuir a factores externos los orígenes del crecimiento. Aunque el estado de investigación sobre la economía castellana durante el siglo XV no permite todavía datar con precisión el momento de arranque del 
crecimiento ni los factores endógenos de éste, la mayor parte de los especialistas del siglo xv castellano sostiene que el despegue económico que se inicia en la centuria es el resultado afortunado de la superación de "la crisis del siglo xiv», superación que en el caso castellano se basó en buena medida en la inserción de la economía castellana en los circuitos del comercio europeo, gracias a la exportación, sobre todo, de lana merina de los rebaños de la Mesta, pero también de productos agrarios de las grandes fincas del valle del Guadalquivir y de productos metalúrgicos del País Vasco.

Aunque el arranque del crecimiento fue resultado de factores internos y fue anterior a la integración de Castilla en el ámbito imperial y al impacto de la explotación colonial de las Indias americanas, es indiscutible que conforme avanza el siglo xvi la economía castellana estuvo cada vez más condicionada, para bien y para mal, por el hecho imperial y colonial, según se verá más adelante.

Analicemos ahora cómo se concretó la coyuntura cambiante en los principales sectores de la realidad económica castellana en los siglos XVI y XVII.

\section{La población}

Tras el estancamiento demográfico que, según parece, caracterizó el primer tercio del siglo xvi, la población española creció de forma sostenida hasta las últimas décadas de la centuria. Se calcula, a la vista de los recuentos de vecinos disponibles - a los que se aplica el coeficiente 4 para la conversión del vecino en habitante-, que hacia 1530 la población española rondaría los 5 millones de habitantes y que en 1591 alcanzaría los 6,8 millones. La población asentada en los territorios de la Corona de Castilla habría pasado entre las mismas fechas de los 4 millones a los 5,6, esto es, se habría incrementado en un 40 por 100 en sesenta años.

La población castellana no creció con la misma intensidad en las diferentes regiones. Mientras que en las regiones septentrionales --Galicia, Asturias, Cantabria - la población casi se dobló entre 1530 y 1591, en las regiones centrales sólo aumentó en un 33 por 100, y en las regiones meridionales - Andalucía- en un 50 por 100 aproximadamente. Parece que estos contrastes en la intensidad del crecimiento obedecen a la diversa densidad poblacional en el momento inicial de la expansión: a una baja densidad previa en el Norte corresponde un mayor crecimiento posterior, y a la inversa en el área central.

Aunque tanto la población rural como la urbana experimentaron aumento, fue la urbana la que creció con mayor intensidad, como lo muestra el hecho de que el número de habitantes de una cuarentena de núcleos urbanos castellanos se incrementó en aproximadamente un 75 por 100 entre 1530 y 1591 (Fernández Alvarez), siendo así que la población total sólo se incrementó en un 40 
por 100 , según se acaba de indicar. Esta constatación sugiere que la expansión se basó más en el crecimiento de las actividades manufactureras y comerciales, centradas en los núcleos urbanos, que en el auge de la actividad agraria, aunque ésta también creciera. Naturalmente, es el éxodo rural hacia las ciudades lo que explica el fuerte incremento poblacional de éstas: su florecimiento industrial y comercial atrajo a la población campesina.

Entre las ciudades que crecen, los casos de Madrid y Sevilla son, sin duda, los más espectaculares. La villa de Madrid, convertida en centro político-administrativo de la Monarquía al decidir Felipe II situar allí la Corte en 1561, pasó de los escasos 20.000 habitantes en dicha fecha a los 90.000 en los años postreros del siglo, según la investigación reciente de $M{ }^{a}{ }^{2}$ Carbajo Isla. Sevilla, centro del comercio con América desde que en 1503 se creara en la ciudad la Casa de Contratación, aumentó su población de los 25.000 habitantes a los casi 75.000 entre 1530 y 1591 .

Es importante subrayar que el crecimiento de la población castellana en el siglo xvi se ajustó a los caracteres del «modelo demográfico antiguo» con su alta natalidad, elevada mortalidad y periódicas crisis de mortalidad extraordinaria que han sido estudiadas recientemente por V. Pérez Moreda. El crecimiento no estuvo acompañado ni motivado por cambios revolucionarios en el comportamiento demográfico.

Alrededor de los años ochenta del siglo, el crecimiento de la población castellana se detiene y se inicia a continuación un fuerte descenso, en el que los estragos provocados por la peste bubónica de 1598-1602 -causó unas 500.000 muertes - fue sólo uno de los factores, dado que el declive de la población tenía motivaciones bastante menos coyunturales y bastante más estructurales que el contagio epidémico, según se verá más adelante. Tampoco cabe atribuir demasiada incidencia en el descenso de la población a la emigración castellana hacia América, que fue modesta, según advierte J. Nadal, sintetizando los resultados de los trabajos de P. Boyd-Bowman, ni a la expulsión de los moriscos de 1609-1611, que, según demuestran A. Domínguez Ortiz y B. Vincent, sólo provocó la salida de los territorios castellanos de unas 90.000 personas.

Es aventurado, en el estado actual de las investigaciones, cuantificar con seguridad cuál fue la pérdida demográfica sufrida por Castilla entre fines del xvi y mediados del xvil, que es cuando el movimiento descendente de la población toca fondo. Con todas las reservas necesarias se puede, sin embargo, adelantar que hacia 1650 sólo se contabilizarían entre 4,2 y 4,5 millones de habitantes, esto es, entre un 20 y un 25 por 100 menos de los 5,6 millones de 1591.

El descenso demográfico fue especialmente intenso en los centros urbanos de las regiones castellanas centrales, salvo en el caso de Madrid. Muchas de las 
ciudades y villas perdieron en el lapso de cincuenta años la mitad de los habitantes que tenían en 1591 - Segovia, Medina de Rioseco, Avila, Salamanca, Toledo, Badajoz-, y otras incluso sufrieron mayores pérdidas - Valladolid, Medina del Campo, Burgos, Palencia, Cuenca-. En cambio, según Fernández Alvarez, los núcleos urbanos de las regiones castellanas septentrionales y meridionales parecen haber mantenido su población, lo que no invalida la conclusión general de que la caída de la población castellana en el siglo xvir fue un hecho que afectó con mayor dureza a los centros urbanos y de que, por consiguiente, fue una secuela de la decadencia de las actividades industriales y comerciales.

En la segunda mitad del siglo xvir, el contingente poblacional de los centros urbanos no experimentó variaciones apreciables a partir del estado en que había quedado hacia 1650 , pero la población rural conoció un ascenso claro que en las regiones septentrionales - Galicia y Asturias especialmente- adquirió rasgos verdaderamente espectaculares, según se desprende de las series disponibles de bautismos recogidas en los archivos parroquiales. Es opinión generalizada que la brillante recuperación de la población en las regiones del Norte en la segunda mitad del xvir se debió a las positivas transformaciones introducidas en el aprovechamiento de la tierra a raíz de la difusión del cultivo del maíz. Para Asturias puede verse el trabajo de Sanzo Fernández; una buena síntesis sobre el impacto del cultivo del maíz en las economías rurales del Norte es la de G. Anes.

\section{La agricultura y la ganaderia}

El crecimiento demográfico castellano del siglo xvi se sincronizó con un paralelo incremento de la producción agrícola - cereales especialmente-. El aumento de las cosechas se basó en la extensión de la superficie cultivada a costa de la reducción de la superficie de pasto y monte. La expansión de la producción agraria, inducida por el alza de la demanda de alimentos consiguiente al aumento de los habitantes, no fue, por tanto, resultado de transformaciones en los métodos de cultivo, sino que se ajustó al clásico modelo extensivo. La progresiva sustitución de los bueyes por las mulas como animal de trabajo, tan comentada por los coetáneos, no puede considerarse como un cambio tendente a incrementar los rendimientos, sino que respondía a la necesidad de cultivar tierras cada vez más alejadas de los lugares de residencia de los campesinos - las mulas son más rápidas - y a la disminución de las zonas de pasto - los bueyes se alimentan, sobre todo, en prados naturales.

Gracias a la buena calidad de la documentación castellana sobre el cobro del diezmo eclesiástico, se conoce con bastante precisión el movimiento de la producción agraria en los siglos xvi y xvir. Así, para la extensa circunscripción 
territorial del Arzobispado de Toledo - casi toda Castilla la Nueva-, las series decimales describen un continuado ascenso de la producción de cereales de 1460 a 1560 , sitúan entre 1560 y 1580 el momento culminante de la expansión, reflejan desde 1580 un descenso de la producción que toca fondo hacia $1640-1650$ y testimonian para la segunda mitad del siglo un estancamiento de los niveles de las cosechas o un modesto ascenso a partir de la situación depresiva alcanzada en 1640-1650, según las comarcas. Este esquema de la evolución de la producción de cereales es válido para la mayoría de los territorios castellanos en sus grandes tendencias, aunque en algunos - Segovia, por ejemplo (García Sanz, 1977) - la recuperación de la segunda mitad del siglo xvil fue más vigorosa que en tierras del Arzobispado de Toledo.

El aumento de la producción cerealista - y también de vino- hasta 1580 , en base a la extensión de los cultivos a nuevas tierras, desencadenó una serie de consecuencias que, a la postre, van a frenar la expansión productiva. La renta de la tierra se disparó, beneficiando a los terratenientes - nobles y eclesiásticos, sobre todo, pero también un grupo de propietarios territoriales no privilegiados- y deteriorando las condiciones de vida de los campesinos (Salomon). Los precios agrarios subieron, y no sólo como consecuencia de la presión de la demanda o, como sostenía E. J. Hamilton, del aumento de la masa monetaria a raíz de la llegada de las remesas de metales preciosos americanos, sino también, y sobre todo, por el alza de los costes de producción consiguiente a la repercusión de los rendimientos decrecientes obtenidos en tierras de calidad cada vez peor sobre las que se extiende el cultivo. También la ganadería se vio negativamente afectada al reducirse las zonas de pasto: el que el contingente ovino trashumante encuadrado en la Mesta decreciera a partir del primer tercio del siglo XVI, pasando de los 3 millones de cabezas a menos de 2, según mostró J. Klein y, más recientemente, ha corroborado J. P. Le Flem, es un testimonio claro de las dificultades que padeció la ganadería.

El hecho de que la expansión agraria del siglo xvi se realizase sin transformaciones cualitativas en los métodos de cultivo, transformaciones que hubieran supuesto fuertes inversiones que eran impensables dada la estructura de clases vigente, desencadenó estos procesos negativos que acabaron por frenar la propia expansión agraria y depararon una larga depresión en los campos castellanos durante casi todo el siglo xvil, que fue objeto de interesantes reflexiones por parte de «arbitristas» coetáneos como Lope de Deza, en su Gobierno político de agricultura (Madrid, 1618), y Miguel Caxa Leruela, en su Restauración de la abundancia en España (Nápoles, 1631).

A pesar de que la depresión agraria preside la mayor parte del siglo XviI castellano - caída de la producción reflejada en las series decimales, descenso de la renta, abandono de las tierras de cultivo, despoblación de algunos lugares, estancamiento de precios en medio de fuertes fluctuaciones motivadas por 
las manipulaciones monetarias, etc.- es preciso señalar que en las regiones castellanas septentrionales se produjo a lo largo del siglo una importante transformación del régimen de cultivos al difundirse la producción del maíz, lo que permitió un aprovechamiento más intenso del suelo y una mayor producción agraria global, al intercalarse el cultivo del maíz con los cultivos ya tradicionales. No obstante lo dicho, parece excesivo valorar la introducción del maíz como un hecho revolucionario. En realidad -y como luego ocurrirá también con la patata-, la difusión del nuevo cultivo sólo sirvió para elevar el techo de resistencia de una sociedad acusadamente tradicional ante las amenazas malthusianas. A pesar de esta consideración, es razonable atribuir a la difusión del cultivo del maíz el vigoroso crecimiento demográfico de Galicia y Asturias en la segunda mitad del siglo xvir.

Es aún mal conocida la historia de la ganadería castellana durante el siglo xviI. Se puede afirmar, sin embargo, con relativa seguridad que los ganados estantes - aquellos que pastan durante todo el año en el territorio de la misma localidad donde reside el propietario- aumentaron al disponer de mayor superficie de pasto, como consecuencia de la regresión del cultivo; los ganados trashumantes - lanares fundamentalmente, que pacen durante el invierno en las dehesas de Extremadura y La Mancha y pasan el verano en los agostaderos del Norte, trasladándose de las dehesas a los agostaderos a través de las cañadas de la Mesta- no se incrementaron, dado que la coyuntura comercial en los mercados exteriores _-el de Amsterdam era uno de ellos y la lana merina llegó a ser un valor cotizado en su Bolsa, según se puede apreciar en la célebre obra de N. W. Posthumus sobre los precios holandeses - fue adversa para la lana castellana durante buena parte del siglo xvir (Bilbao y Fernández de Pinedo, 1982).

A manera de conclusión sobre este apartado, se puede afirmar que el modelo de expansión agraria seguido en Castilla en el siglo xviI se ajustó a los supuestos ya tradicionales y reiterados en toda fase de crecimiento de una economía y una sociedad de Antiguo Régimen; en los siglos XI-XIII había ocurrido un proceso similar, y se volverá a repetir en el siglo xvirr. Las limitaciones de este modelo, derivadas de los caracteres de la estructura de clases dominante, explican básicamente la depresión del siglo XVII.

\section{La producción artesano-industrial}

El incremento demográfico y la expansión agraria hasta las últimas décadas del siglo XVI estimularon la producción de manufacturas. Efectivamente, investigaciones recientes han demostrado cómo los muy importantes centros industriales de Segovia y Córdoba conocieron en el siglo xvi un considerable crecimiento de la producción industrial textil. La producción de paños de Se- 
gocia hacia 1585 era aproximadamente la misma en cantidad y calidad que la que por entonces se obtenía en ciudades como Florencia o Venecia: unos 16.000 paños anuales de 33,4 metros de largo cada uno (véanse García Sanz, 1977; Fortea, 1981, y Ruiz Martín, 1965-67).

La producción industrial creció a lo largo del siglo xvi, pero simultáneamente experimentó profundas transformaciones, tanto en la organización productiva como en la calidad de los géneros fabricados. El caso del textil lanero en Castilla la Vieja y León es el mejor conocido al respecto. En virtud de las Ordenanzas Generales de 1511 sobre fabricación de paños, la producción antes dispersa por el medio rural en dichas regiones se fue concentrando para las operaciones de tejido y apresto en las ciudades y núcleos importantes, mientras que las operaciones previas siguieron realizándose en el campo, aunque ahora bajo la dependencia financiera de los «mercaderes hacedores de paños» residentes en las ciudades, que lograron articular en su propio beneficio el Verlagssystem; la organización gremial, muy débil hasta entonces en Castilla la Vieja y León en lo tocante a actividades textiles, experimentó un fuerte avance; en fin, la calidad de los géneros producidos mejoró sensiblemente, de forma que hasta 1585 casi todos los paños confeccionados en Segovia eran de la clase de los Veintedosenos, siendo así que cien años antes apenas se alcanzaban a producir en la ciudad paños Dieciochenos. Esta transformación en la calidad de los tejidos obedecía a un cambio en la demanda, cada vez más solícita de artículos de mejor calidad como consecuencia de la onda de prosperidad que por entonces vivía Castilla.

De menor entidad fueron las transformaciones de la industria textil lanera y sedera en Castilla la Nueva y Andalucía - Toledo, Cuenca, Córdoba, Granada-, habida cuenta de que en estas regiones la urbanización y gremialización de la producción eran herencia de la época medieval, según comprueba Iradiel (1974).

No faltan testimonios de que, en los casos de Segovia y Córdoba, el Verlagssystem o Domestic System fue superado en los momentos culminantes de la expansión del siglo xvi —entre 1560 y 1590_, llegándose a organizar la producción a la manera del Factory System, con todas las operaciones de fabricación concentradas en un mismo establecimiento y con mano de obra asalariada. En cualquier caso, fue el capital comercial, personificado en los «mercaderes hacedores de paños», el que controlaba el proceso productivo y la fase de comercialización, de forma que la actividad manufacturero-artesanal no llegó a generar una acumulación de capital industrial propiamente dicho.

Como, según ya hemos visto, ocurre con la población y la producción agraria, en las últimas décadas del siglo xvi la expansión industrial se detiene o inicia una grave recesión. Así lo testimonian los casos de Segovia, Córdoba y, también, Toledo. No sólo decrece la producción en términos cuantitativos, 
sino que, además, desciende considerablemente la calidad de los artículos, a fin de adaptarse a las posibilidades de consumo de unos demandantes menos prós. peros y más pobrẹs que los del siglo xvi. En 1625, los fabricantes de Segovia y Palencia proyectan producir masivamente bavetas en lugar de los tradicionales y selectos Veintedosenos. Sobre estas cuestiones véanse Sánchez (1981) y García Sanz (1977).

Se han aducido numerosas causas para explicar la decadencia industrial del siglo xvir: la previa contención del crecimiento agrario; la presión fiscal, que encareció notablemente los artículos de subsistencia de los menestrales, repercutiendo en el alza de los salarios; la actitud en las Cortes de los representantes de las ciudades, que propugnaban una política más favorable al consumidor - condescendencia con importaciones de manufacturas a fin de que bajaran los precios- que al productor - política proteccionista-; el enfrentamiento entre artesanos y «mercaderes hacedores de paños» - comprobado en Córdoba con claridad-; la fuerte alza de los precios españoles ante el impacto inflacionista del "tesoro americano», que propició la entrada de mercancías extranjeras. A estos factores de la decadencia habría que añadir uno que parece de gran trascendencia: el hecho, ya señalado, de que el capital comercial controlara el proceso productivo. Al no hallarse comprometidos con la suerte de la actividad industrial, dado que era escasa la inversión en capital fijo realizada —el Verlagssystem presenta esa característica-, los «mercaderes hacedores de paños" tenían las manos libres para aplicar su capital a cualquier otra actividad en cuanto surgieran dificultades. Digamos que su posición en el proceso productivo facilitaba o hacía escasamente dolorosa una «deserción». Esto fue lo que, desde luego, ocurrió con buena parte de los «mercaderes hacedores de paños» de Segovia, que en el siglo xvir dedicaron sus caudales preferentemente a la exportación de lana, apartándose de la fabricación de paños, según consta de testimonios bien explícitos.

\section{El comercio}

El comercio interior castellano en los siglos xvi y xvir no ha sido objeto de investigaciones específicas, aunque existen multitud de referencias al tema dispersas en las publicaciones existentes. Se comprende así que sea difícil afirmar sobre esta cuestión algo más que lo que cabe deducir por mera lógica: que la actividad comercial interior fue más intensa en el siglo xvi que en el XviI, habida cuenta de que en esta centuria perdieron importancia los núcleos urbanos como centros de consumo. También hay que señalar que la conversión de la villa de Madrid en capital política de la Monarquía en 1561 y su rápido crecimiento demográfico hasta 1630 —alcanzó entonces unos 
130.000 habitantes - determinó la reorientación del tráfico mercantil de todo el interior de la Península: el abastecimiento de Madrid absorbió buena parte de los excedentes agrarios de Castilla la Vieja, León y La Mancha, según ha estudiado Ringrose.

Una atención más sistemática ha sido prestada al comercio exterior, tanto al sostenido con el resto de Europa como al relacionado con las colonias de América. Los estudios de Vázquez de Prada, Chaunu, Ruiz Martín, Basas, Lapeyre, García Fuentes y Lorenzo Sanz así lo testimonian.

La estructura del comercio exterior castellano en los siglos XVI y xVII era la característica de un país económicamente atrasado: predominaban en el conjunto de las exportaciones las materias primas - lana fina merina, sobre todo, que se dirigía a los mercados europeos- y los productos agrarios - vino, aceite y aguardiente, que se remitían sobre todo a las colonias americanas-; las manufacturas constituían el renglón más importante de las importaciones. $\mathrm{La}$ insuficiencia de la producción doméstica de manufacturas era evidente $\mathrm{y}$, conscientes de ello, ni las Cortes ni los gobernantes tomaron medidas verdaderamente eficaces para evitar la entrada de manufacturas extranjeras.

Burgos, con su Consulado de Comercio creado en 1494 y con sus ricos mercaderes, era la ciudad que canalizaba las relaciones comerciales de Castilla con el resto de Europa, y en especial con los Países Bajos. Las grandes ferias de Medina de Rioseco, Villalón, Benavente y, sobre todo, Medina del Campo fueron plazas de contratación y de pagos integradas en este eje comercial del Norte, el cual conoció una etapa de gran prosperidad hasta los años sesenta del siglo xvi. En esta coyuntura próspera influyó el hecho de que los acreedores de la Hacienda castellana - hombres de negocios extranjeros sobre todohubieron de colocar fuera del país los pingües beneficios que conseguían en sus operaciones recurriendo a extraer mercancías, dado que no se les concedía, salvo excepciones, «licencias de saca» de la moneda, según ha estudiado Ruiz Martín. A partir de los años sesenta, la actividad comercial en la zona experimentó una larga depresión de la que ya no se recuperaría jamás. Ello fue consecuencia no sólo de una mayor condescendencia respento a la salida de la moneda, sino sobre todo de las dificultades que para el tráfico de mercancías supuso la guerra de los Países Bajos. El volumen del comercio disminuyó tablemente -el mercado italiano fue el principal destinatario de las lanas, a través de los puertos levantinos-; Burgos sufrió un espectacular descenso de población, ya en el siglo xvir, y otro tanto ocurrió en Medina del Campo, Medina de Rioseco, Benavente y Villalón, cuyas ferias languidecieron, como muestran Marcos (1978) y Yun (1983).

salvo excepciones, «licencias de saca» de la moneda. A partir de los años sesenta, la actividad comercial en la zona experimentó una larga depresión de la que ya no se recuperaría jamás. Ello fue consecuencia no sólo de una mayor 
Sevilla, en el Sur, con su Casa de Contratación, canalizaba el comercio con las colonias americanas, aunque en el siglo xvir fue cobrando creciente importancia Cádiz - en 1680 se trasladó a esta ciudad la cabecera de las flotas que atravesaban el Atlántico- A partir de los estudios ya citados de $P$. Chaunu y de L. García Fuentes es posible reconstruir la evolución del movimiento comercial con América, que no dejó de crecer hasta 1610, sufrió un hundimiento creciente hasta 1660 y después inició una lenta recuperación. Pero quizá sea de mayor interés señalar que el tráfico comercial con América fue progresivamente cayendo bajo el control de mercaderes extranjeros, que se valían de españoles como testaferros, y que buena parte de las mercancías remitidas habían sido importadas previamente de otros países de Europa - se trataba, pues, de reexportaciones-. Es bien conocido que a fines del siglo xvil los franceses proporcionaban el 25 por 100 de las mercancías remitidas a América, el 22 por 100 los genoveses, el 20 por 100 los holandeses, el 11 por 100 los flamecos, otro tanto los ingleses y un 8 por 100 los alemanes.

Este hecho es un testimonio evidente de la incapacidad del capital comercial castellano para promover una producción doméstica capaz de abastecer la demanda colonial y de sentar las bases para el crecimiento económico de la metrópoli, lo que constituía uno de los postulados de las políticas mercantilistas.

\section{La Hactenda, el "capitalismo cosmopolita» y la economía castellana}

La historia de la Hacienda castellana en los siglos xvi y xvil es, sin duda, el tema económico mejor cubierto por investigaciones. Las obras monográficas de Ladero Quesada, Carande, Ulloa, Domínguez Ortiz, Ruiz Martín, Garzón Pareja y Artola permiten seguir con bastante precisión los avatares de las finanzas estatales desde fines del siglo xv a fines del xvir.

El coste financiero del Imperio español cargó fundamentalmente sobre la Hacienda de Castilla, pero la Hacienda castellana, configurada durante la época medieval para atender las necesidades de un Estado de modesta envergadu$\mathrm{ra}$, se vio desbordada desde el reinado del emperador Carlos $\mathrm{V}$ por las cuantiosas exigencias financieras derivadas del hecho imperial. Aunque la presión fiscal no dejó de crecer en base a incrementar los viejos impuestos y a crear otros nuevos —el Servicio de los Millones, establecido en 1590, fue el más importante de éstos-, el déficit presupuestario fue crónico.

Como es habitual en tales circunstancias, el recurso a la creación de deuda pública se impuso como medio de cubrir el déficit entre ingresos fiscales regulares y gastos efectivos. Dos fueron los tipos de deuda generada por la Hacienda castellana: la deuda consolidada, consistente fundamentalmente en juros 
- títulos a medio y largo plazo, la suma de cuyos intereses, el situado, llegó a consumir la totalidad de los ingresos procurados por las «rentas» ordinarias-, y la deuda flotante, consistente básicamente en contratos de préstamo llamados asientos que suscribían banqueros y hombres de negocios españoles $\mathrm{y}$, sobre todo, extranjeros - personificación del denominado «capitalismo cosmopolita».

Sobre la situación de los acreedores extranjeros de la Hacienda castellana ha escrito Ruiz Martín ( 1965 b): «El capitalismo cosmopolita tornó sus miras hacia Castilla, si no inmediatamente de los viajes colombinos, desde que la llegada de metales indianos fue en cuantía suficientes para remediar la escasez monetaria que venía padeciendo Europa... El capitalismo cosmopolita, para introducirse en España, utiliza el vehículo de los asientos con Carlos V, garantizados por el tesoro castellano.» Aproximadamente la cuarta parte de los metales preciosos traídos de América venía destinada a la Hacienda. Son estos metales, que no supusieron en los mejores momentos más de un 25 por 100 de los ingresos fiscales de la Hacienda, los que atraen a los banqueros extranjeros.

Durante el reinado de Carlos V, el 40 por 100 del dinero de los asientos fue proporcionado por italianos, el 35 por 100 por alemanes y sólo un 16 por 100 por españoles (Carande). Pero los italianos - exactamente genoveses-acabarán destacándose claramente como los máximos acreedores en el reinado de Felipe II y Felipe III, y nunca dejarán de estar presentes, aunque en el reinado de Felipe IV los judíos conversos portugueses, que actúan como agentes de los hombres de negocios holandeses, llegaron a eclipsar a los genoveses, como pone de manifiesto Ruiz Martín (1970).

Esta dependencia permanente de los servicios financieros de la banca extranjera evidencia la inmadurez del capitalismo castellano, que le incapacitó para aprovechar su excelente posición para beneficiarse de las debilidades de la Hacienda. Felipe II convocó en varias ocasiones a los banqueros castellanos a fin de que suplieran a los genoveses, pero los capitales castellanos no acudieron a la llamada, según ha investigado Ruiz Martín (1965 b). También fracasaron varios proyectos - en 1560 y en 1622 - de crear un banco estatal o paraestatal, y en este fracaso influyó mucho la desconfianza de las Cortes, que temían que la realización del proyecto proporcionaría una peligrosa independencia a los monarcas a la hora de decidir sobre la intervención militar en el exterior.

Los efectos de la carga financiera impuesta por el sostenimiento del Imperio fueron fatales para la economía castellana. La Hacienda absorbió a través de los juros buena parte de los ahorros de los particulares, desviándolos de la inversión productiva. Por otra parte, la presión fiscal creciente deprimió la demanda, al reducir el dinero disponible para el gasto y al incrementar el precio 
de los artículos de consumo -así operaron los impuestos de alcabala, los cientos y la sisa del Servicio de los Millones-. Pero, además, con el supremo propósito de obtener recursos al precio que fuera, se recurrió a prácticas que no sólo provocaron un grave y directo perjuicio a la actividad económica - caso de la venta de tierras baldías comunales a los pueblos, estudiada recientemente por Vassberg, o de la manipulación de la moneda, por ejemplo-, sino que atentaron contra la misma estructura política v social del reino - caso de la venta de títulos, de la venta de lugares de realengo que se convierten en señoríos, por ejemplo-, como ha estudiado Domínguez Ortiz (1964).

La desproporción entre las grandes exigencias financieras del Estado imperial, por una parte, y, por otra, la menguada capacidad tributaria de la economía, junto con la ineficacia de la Hacienda, desencadenaron una serie de procesos que pusieron en peligro la estabilidad misma del Estado. Sin embargo, éste se mantuvo y contó con el apoyo social de grupos que se beneficiaban de la situación.

\section{LA SOCIEDAD: LA DESERCION DE LA BURGUESIA Y EL TRIUNFO DE LA ARISTOCRACIA}

La cuestión central de la historia social —y también política- de Castilla en los siglos Xvi y xviı es el análisis del proceso por el que una burguesía ascendente hasta las últimas décadas del 500 fracasa como clase y, a continuación, la aristocracia - la nobleza en sentido amplio, en la que se incluyen «nobles nuevos» procedentes de la burguesía que ha abandonado las actividades económicas y la mentalidad que le eran características - pasa a desempeñar un papel incontestado en el reino, especialmente durante el mandato de Felipe IV (1621-1665). El siglo xviI, que en otros países europeos fue el siglo de «la crisis de la aristocracia», en expresión popularizada por Stone refiriéndose a Inglaterra, fue en Castilla el siglo del «triunfo de la aristocracia».

En este proceso de ascenso frustrado de la burguesía y de triunfo aristocrático influyeron fundamentalmente dos factores: en primer lugar, la coyuntura económica, que, como ya se ha analizado, deparó condiciones objetivas favorables al ascenso burgués hasta las últimas décadas del siglo xvi y después fue adversa a dichas condiciones estimulantes; en segundo lugar, los problemas financieros de la Hacienda real —esto es, el Estado-, que desde el reinado de Felipe II hubo de arbitrar medidas para conseguir dinero que significaron la claudicación frente a la ofensiva aristocrática, la cual, así, recibió alientos.

Refiriéndose a la burguesía castellana en la etapa de pujanza, Pierre Vilar (1964) ha escrito con acierto que: 
«Una naciente burguesía pudo haberlo hecho -invertir en sentido capitalista e instaurar relaciones sociales nuevas-, y de 1480 hasta 1550 , aproximadamente, la burguesía no falta a la cita. Sólo que, por su posición en el circuito del dinero, ha experimentado, primeramente, el capitalismo inestable de los puertos y de las ferias. Por otro lado, las "fuerzas productivas" de que disponía -tierras, hombres, innovaciones tecnológicas - tropezaron muy pronto en las mesetas de Castilla con la ley de los rendimientos decrecientes. De ahí el efecto esterilizante de las inyecciones monetarias después de 1550 . Se gasta, se importa, se presta dinero a interés, pero se produce poco. Precios y salarios dan grandes saltos. Se desarrolla el parasitismo y la empresa muere. Es la miseria para el día de mañana.»

De la influencia social y política de la burguesía castellana en los buenos momentos es testimonio la «Revolución de las Comunidades» (1520-1521), episodio histórico sumamente complejo, pero en el que las burguesías urbanas tuvieron un protagonismo indudable, según ha estudiado J. Pérez.

Mientras el elemento burgués se beneficiaba de la coyuntura de prosperidad durante buena parte del siglo xvi, la aristocracia sufrió los estragos de la «Revolución de los Precios», que redujo considerablemente sus ingresos reales. A ello habría que agregar la actitud, cuanto menos independiente, de Carlos V y de Felipe II respecto a la aristocracia.

Esta situación cambió radicalmente en las últimas décadas del siglo. Como ocurre también en otras sociedades mediterráneas de la época, la burguesía va a apartarse progresivamente de sus actividades económicas típicas y va a hacer todo lo posible por dotarse de nuevas bases económicas similares a las que disfruta la aristocracia: es «la traición de la burguesía», en afortunada expresión acuñada por Braudel. La renta de la tierra, los intereses de los préstamos, las mercedes de los reyes, los ingresos desviados o "enajenados» de la Hacienda real, los ingresos procurados por el ejercicio del poder señorial constituirán las principales fuentes de ingresos de esa barguesía que deserta. Naturalmente, en este contexto, la aristocracia recupera su sólida posición económica, social y también política desde que, a partir del reinado de Felipe III, los monarcas han de contar con la aristocracia para afianzar su gobierno. La actitud antiaristocrática del conde-duque de Olivares iba contra corriente y fue desbordada.

La calamitosa situación de la Hacienda real desde las últimas décadas del siglo xvi favoreció sobremanera este proceso de cambio social. El Estado hubo de hacer concesiones. El caso del otorgamiento por parte del rey de las Condiciones de los Millones, esto es, la concesión a las ciudades de cuanto pedían sus representantes en Cortes como condición para pagar el impuesto del Ser. 
vicio de los Millones, es sumamente representativo en este sentido. $\mathrm{Y}$ hay que tener en cuenta que los representantes de las ciudades desde fines del XvI eran ya exclusivamente portavoces de la aristocracia urbana, la vieja y la nueva que procedía de las filas de la antigua burguesía.

Esto es, en síntesis, lo que se desprende de los recientes estudios de Thompson, Jago, Fernández Albaladejo y Cavillac.

Me parece conveniente concluir con las oportunas palabras de Vilar:

«Y desde 1570 hay que luchar contra los propios súbditos del rey: abriendo el abismo de las guerras de Flandes, los "gueux" lanzan el reto de la "nación" burguesa ya más adelantada al "imperio" católico y feudal de Felipe II. Así el imperialismo español ha sido en realidad "la etapa suprema" de la sociedad que él mismo ha contribuido a destruir. Pero, en su propio solar, en Castilla $y$ hacia 1600 , el feudalismo entra en agonia sin que exista nada a punto para reemplazarle. Y este drama durará. Dura todavía, y por eso Don Quijote sigue siendo un símbolo.»

\section{BIBLIOGRAFIA SELECCIONADA}

ANEs, Gonzalo (1970): Las crisis agrarias en la España moderna, Madrid.

- (1978): «La "depresión" agraria durante el siglo xvil en Castilla», Homenaje a Julio Caro Baroja, Madrid.

- (1980): Historia de Asturias. Edad Moderna, II, Vitoria.

Artola, Miguel (1982): La Hacienda del Antiguo Régimen, Madrid.

Basas, Manuel (1963): El Consulado de Burgos en el siglo XVI, Madrid.

Bennassar, Bartolomé (1967): Valladolid au Siècle d'Or. Une ville de Castille et sa cam. pagne au XVI siècle, París.La Haya (ed. en castellano, Valladolid, 1983).

- (1969): Recherches sur les grandes épidémies dans le Nord de l'Espagne à la fin du XVI siècle, París.

Bilbao, Luis María, y Fernández de Pinedo, Emiliano (1982): Exportations des laines, trasbumance et ocupation de l'espace en Castille aux XVI, XVII et XVIII' siècles, comunicación al VIII Congreso Internacional de Historia Económica, Budapest.

Braudel, F. (1976): El Mediterráneo y el mundo mediterráneo en la época de Felipe II, Madrid.

Brumont, Francis (1984): Campo y campesinos de Castilla la Vieja en tiempos de Felipe II, Madrid.

Carande, Ramón (1965): Carlos $V$ y sus banqueros, I: “La vida económica de Castilla (1516-1556)», Madrid.

Carbajo Isla, M." (1984): La población de la villa de Madrid, $1594-1840$ (tesis de Doctorado, aún inédita, defendida en febrero de 1984 en la Universidad Complutense de Madrid).

Cavillac, M. (1983): Gueux et marchands dans le Guzmán de Alfarache (1599-1604), Bordeaux. 
Chaunu, Pierre y Huguette (1955-1960): Seville el l'Atlantique, 1504-1650, París.

Domínguez ORtiz, Antonio (1948): «La ruina de la aldea castellana», Revista Internacional de Sociologia.

- (1951-1952): «La desigualdad contributiva en Castilla durante el siglo xvil», Anuario de Historia del Derecho Español.

- (1960): Politica y Hacienda de Felipe IV, Madrid.

- (1963): La sociedad española del siglo XVII, Madrid.

- (1964): «Ventas y exenciones de lugares durante el reinado de Felipe IV», en Anuario de Historia del Derecho Español, XXXIV.

- (1984): Politica fiscal y cambio social en la España del siglo XVII, Instituto de Estudios Fiscales, Madrid.

Domínguez Ortiz, Antonio, y Vincent, B. (1978): Historia de los moriscos Vida y tragedia de una minoria, Madrid.

Elliotr, John H. (1965): La España Imperial, 1469-1716, Barcelona.

- (1982): Poder y sociedad en la España de los Austrias, Barcelona

Fernández Albaladejo, Pablo (1982): «Monarquía y Reino en Castilla, 1538-1623», comunicación a la XIV Settimana di Studio del Instituto Internazionale di Storia Economica "Francesco Datini", Prato, inédito.

- (1984): «Monarquía, Cortes y "cuestión constitucional" en Castilla durante la Edad Moderna", Revista de las Cortes Generales, 1.

Fernández Alvarez, Manuel (1984): La sociedad española en el Siglo de Oro, Madrid.

Fortea PÉrez, José Ignacio (1981): Córdoba en el siglo XVI: las bases demográficas y económicas de una expansión urbana, Córdoba.

García Fuentes, Lutgardo (1980): El comercio español con América, 1650-1700, Sevilla.

García SAnz, Angel (1977): Desarrollo y crisis del Antiguo Régimen en Castilla la Vieja. Economia y sociedad en tierras de Segovia, 1500-1814, Madrid.

- (1980): «Bienes y derechos comunales y el proceso de su privatización en Castilla durante los siglos xvi y xviI: el caso de tierras de Segovia», Hispania, 144.

García Sanz, Angel, y Sanz Fernández, Jesús (1984): "Evolución económica de Castilla y León en las épocas moderna y contemporánean, Papeles de Economia Española, 20.

Garzón Pareja, Manuel (1981): La Hacienda de Carlos II, Madrid.

GuIlarte, Alfonso María (1962): El régimen señorial en el siglo XVI, Madrid.

Hamilton, E. J. (1975): El tesoro americano y la revolución de los precios en España, 1501-1650, Barcelona (1.* ed. en inglés, 1934).

HueTz de Lemps, Alain (1967): Vignobles et vins du Nord-Ouest de l'Espagne, Bordeaux, 2 vols.

Iradiel Murugarren, Paulino (1974): Evolución de la industria textil castellana en los siglos XIII-XVI, Salamanca.

JAGO, C. (1979): "The "crisis of the aristocracy" in seventeenth-century Castile», Past and Present, 84.

- (1973): «The influence of Debt on the Relations between Crown and Aristocracy in seventeenth-century Castile», Ecònomic History Review, 26.

- (1981): «Habsburg Absolutism and the Cortes of Castile», American Historical Review, 86.

KLEIN, Julius (1979): La Mesta. Estudio de la bistoria económica española, 1273-1836, Madrid (1.* ed. inglesa, 1919).

Ladero QuesadA, Miguel Angel (1973): La hacienda real de Castilla en el siglo XV, La Laguna.

LAPEYre, Henri (1955): Une famille de Marchands: les Ruiz, París.

- (1981): El comercio exterior de Castilla a través de las aduanas de Felipe II, Valladolid.

Larraz, José (1943): La época del Mercantilismo en Castilla (1500-1700), Madrid.

LE Flem, Jean Paul (1972): «Las cuentas de la Mesta (1510-1709)», Monedo y Crédito, 121.

López Salazar, Jerónimo, y Martín Galán, Manuel (1981): «La producción cerealista en el Arzobispado de Toledo, 1463-1690", Cuadernos de Historia Moderna y Contemporánea, II. 
Lorenzo Sanz, Eufemio (1979): Comercio de España con América en la época de Felipe II, Valladolid.

Llopis Agelan, Enrique (1980): «Crisis y recuperación de las explotaciones trashumantes: La cabaña del Monasterio de Guadalupe (1597-1679)», Investigaciones Económicas, 13.

Marcos Martín, Alberto (1978): Auge y declive de un núcleo mercantil y financiero de Castilla la Vieja. Evolución demográfica de Medina del Campo durante los siglos XVI y XVII, Valladolid.

NADAL, Jordi (1984): La población española (siglos XVI a XX). Barcelona (ed. corregida y aumentada).

Pérez, J. (1970): La révolution des "Comunidades de Castilla», Bordeaux.

PÉREZ Moreda, Vicente (1980): Las crisis de mortalidad en la España interior, siglos XVI-XIX, Madrid.

RINGRose, D. R. (1969): «Madrid y Castilla, 1560-1850. Una capital nacional en una economía regional», Moneda y Crédito, 111.

- (1983): Madrid and the Spanish Economy, 1560-1850, University of California Press.

Ruiz Martín, Felipe (1965a): Lettres marchandes échangées entre Florence et Medina del Campo, París.

- $(1965$ b): «Un expediente financiero entre 1560 y 1575: La Hacienda de Felipe II y la Casa de Contratación de Sevilla», Moneda y Crédito, 92.

- (1967): «La población española al comienzo de los tiempos modernos», Cuadernos de Historia, 1.

- (1965.1967): “Un testimonio literario sobre las manufacturas de paños en Segovia por 1625», en Homenaje al Profesor Alarcos Garcia, Valladolid.

- (1970): «La Banca en España hasta 1782», en El Banco de España. Una bistoria económica, Madrid.

Salomon, Noel (1964): La campagne de Nouvelle Castille à fin du XVI siècle d'après les «Relaciones Topográficas», París (ed. en castellano, Barcelona, 1973).

SÁNC h EZ SÁnChez, Juan (1981): Toledo y la crisis del XVII, Toledo.

SAnzo Fernández, Carmen María (1982): "La población de Asturias en los siglos xviI a XIX: los registros parroquiales», en La economia española al final del Antiguo Régimen, I: «Agricultura», Madrid.

Thompson, I. A. A. (1979): «The Purchase of Nobility in Castile, 1552-1700", The Journal of European Economic History, vol. 8.

- (1982): «Crown and Cortes in Castile, 1590-1665», Parliament, States and Representation, 2.

UlloA, Modesto (1977): La Hacienda Real de Castilla en el reinado de Felipe II, Madrid

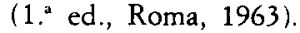

VASSBERG, David E. (1983): La venta de tierras baldias. El comunitarismo agrario y la Corona de Castilla durante el siglo XVI, Madrid.

- (1984): Land and Society in Golden Age Castile, Cambridge Univ. Press.

VázQuez de Prada, Valentín (1960): Lettres marchandes d'Anvers, París.

VIlaR, P. (1964): Crecimiento y desarrollo. Economia e bistoria. Reflexiones sobre el caso español, Barcelona.

Viñas MEY, Carmelo (1941): El problema de la tierra en la España de los siglos XVI y XVII, Madrid.

VV. Aa. (Benítez, R.; Sánchez Blanco; Bilbao, L. M.; Fernández de Pinedo, E.; Casey, J.: Eiras Roel, A.; García Sanz, A.; Garzón Pareja, M.; Lemeunier, G.; Palop Ramos, J. M.; Ponsot, P.; Anés, G., y García Sanz, A.) (1982): Prestations paysannes, dimes, rente toncière et mouvement de la production agricole à l'epoque préindustrielle, París-La Haya (comunicaciones respectivas incluidas en la obra).

Weisser, M. R. (1982): "The Agrarian Depression in Seventeenth-Century Spain", The Journal of Economic History, 42.

Yun Casalilla, Bartolomé (1983): «Feries y mercados: indicadores y coyuntura comercial en la vertiente norte del Duero, siglos xvi-XvII», Investigaciones Históricas, 5. 